\title{
Modeling the Elastic Modulus of 2D Woven CVI SiC Composites
}

Gregory N. Morscher ${ }^{1}$, Ohio Aerospace Institute, Brookpark, OH

\begin{abstract}
The use of fiber, interphase, CVI SiC minicomposites as structural elements for 2D-woven $\mathrm{SiC}$ fiber reinforced chemically vapor infiltrated (CVI) SiC matrix composites is demonstrated to be a viable approach to model the elastic modulus of these composite systems when tensile loaded in an orthogonal direction. The $0^{\circ}$ (loading direction) and $90^{\circ}$ (perpendicular to loading direction) oriented minicomposites as well as the open porosity and excess $\mathrm{SiC}$ associated with $\mathrm{CVI}$ SiC composites were all modeled as parallel elements using simple Rule of Mixtures techniques. Excellent agreement for a variety of 2D woven Hi-Nicalon ${ }^{\mathrm{TM}}$ fiber-reinforced and Sylramic-iBN reinforced CVI SiC matrix composites that differed in numbers of plies, constituent content, thickness, density, and number of woven tows in either direction (i.e, balanced weaves versus unbalanced weaves) was achieved. It was found that elastic modulus was not only dependent on constituent content, but also the degree to which $90^{\circ}$ minicomposites carried load. This depended on the degree of interaction between $90^{\circ}$ and $0^{\circ}$ minicomposites which was quantified to some extent by composite density. The relationships developed here for elastic modulus only necessitated the knowledge of the fractional contents of fiber, interphase and CVI SiC as well as the tow size and shape. It was concluded that such relationships are fairly robust for orthogonally loaded 2D woven CVI SiC composite system and can be implemented by ceramic matrix composite component modelers and designers for modeling the local stiffness in simple or complex parts fabricated with variable constituent contents.
\end{abstract}

\section{INTRODUCTION}

Woven silicon carbide fiber reinforced silicon carbide matrix composites with matrices fabricated by the chemical vapor infiltration route represent a very important

\footnotetext{
${ }^{1}$ Senior research scientist residing at NASA Glenn Research Center, Cleveland, OH
} 
class of materials for a variety of high temperature air-breathing, space, and nuclear applications [1]. Future $\mathrm{SiC} / \mathrm{SiC}$ components will possess rather complex shapes requiring various architectures, differences in local thickness, and local curvature, which may also lead to processing non-uniformities throughout a given component. Needless to say, in order to design with such materials, the effect of geometry, fiber-orientation, architecture, and constituent properties and content on stress-strain response needs to be well understood. The first and the foremost property required for component design is the effect of these factors on tensile elastic modulus. A significant amount of work has been performed towards understanding the mechanical properties of 2D [2-8] and 3D [5] woven CVI SiC matrix composites primarily with regard to the occurrence of non-linear stress-strain behavior due to matrix cracking. However, little has been done to quantify the elastic properties of these composites as a function of architecture, constituent properties, and constituent content. Therefore, the objective of this study was to determine relationships for the elastic modulus of 0/90 2D woven CVI SiC composites in the orthogonal directions for a wide variety of composite parameters by carefully accounting for all those parameters. The parameters included architectural variations, which included composite thickness, number of plies, balanced and unbalanced weaves, and tow size, and constituent variations, which included fiber-type, interphase composition, and constituent contents. In a companion paper [9], the effects of these same architectural and compositional parameters on matrix cracking were studied.

\section{EXPERIMENTAL}

Composite specimens with different CVI SiC matrix content were obtained from several processing approaches/anomalies representing vintages that span over 10 years from the same vendor (currently General Electric Power Systems Composite, Newark, $\mathrm{DE})$. The three general processing approaches are shown schematically in Figure 1 and indicated in Table I. "Standard specimens" went through typical CVI fabrication and machining at General Electric Power Systems Composites, Newark, DE (Figure 1a). This consisted of woven fiber lay-up, CVI interphase infiltration, initial CVI SiC infiltration, specimen machining and a final CVI SiC infiltration step to further densify the specimen. Specimens consisting of eight to 36 plies were fabricated in this manner. Some 
specimens, consisting of eight plies, were infiltrated to less than "full" matrix content ( $50 \%$ ) and not subjected to final CVI SiC infiltration. The open porosity in these low density matrices was filled with epoxy [10] (Figure 1b) for subsequent mechanical testing. In other studies, this fiber-interphase-CVI SiC "preform" makes up the skeleton of higher density composites where the open porosities are filled by SiC slurry and meltinfiltrated silicon composites [11]. However, for the purpose of this study they represent a very low CVI SiC content composite since the epoxy carries negligible mechanical loads. The third set of specimens were "thin panels" that consisted of one, two, or three plies that had delaminated from a multilayer woven $\mathrm{SiC}$ fiber, carbon fiber preform during CVI SiC infiltration [12] (Figure 1c). Even though these specimens were the product of delamination, the delamination occurred early in processing, so that cracking of CVI the $\mathrm{SiC}$ matrix was not observed in polished as-produced specimens.

As indicated in Table I, constituent variations included the woven fiber-type and interphase composition. Composites were fabricated with $\mathrm{Hi}_{-\mathrm{Nicalon}}{ }^{\mathrm{TM}}(\mathrm{HN})$ fibers (Nippon Carbon, Japan) woven at 6.7 tow ends per $\mathrm{cm}$ as a balanced five-harness satin or eight-harness satin weave or Sylramic-iBN fibers (Dow Corning, Midland, MI with a special NASA treatment [13]) woven into balanced (7.9 epcm) or unbalanced (9.4 epcm x $5.5 \mathrm{epcm}$ ) five-harness satin pieces of cloth. Fiber-preforms were either infiltrated with $\mathrm{C}$ or $\mathrm{BN}$ as the interphase. Specimens were machined as dog-bone specimens or straightsided specimens, Table I identifies the specimen geometry of each specimen.

The constituent content was determined for each individual specimen from the mass of the specimens and relative weight gain information obtained from the composite manufacturer. This was necessary because CVI SiC content varies across a panel and some of the specimens were further densified after specimen machining. First, the mass of the as-processed and as-cut specimen was determined*. The dimensions were measured for each specimen shape to determine the specimen volume. The density was

\footnotetext{
* The mass for each specimen was determined in the as-machined ready-to-test state with the exception of the epoxy-infiltrated specimens. The epoxy-infiltrated specimens were weighed after the perform panel was cut into straight-sided specimens and prior to epoxy-infiltration and dogbone machining for constituent determination. The weight of the after-epoxy specimen was measured as well.
} 
determined for each specimen from the mass and specimen volume. The average total fiber volume fraction was determined from the fiber tow and weave properties as follows:

$$
f_{f}=\frac{N_{p l y} N_{f} \pi R_{f}^{2}\left(e p m m_{0}+e p m m_{90}\right)}{t}
$$

where $N_{p l y}$ is the number of woven plies, $N_{f}$ is the number of fibers per tow (500 for HiNicalon and 800 for Sylramic-iBN), $\mathrm{R}_{\mathrm{f}}$ is the average fiber radius $(0.00685 \mu \mathrm{m}$ for $\mathrm{Hi}-$ Nicalon and $0.005 \mu \mathrm{m}$ for Syl-iBN as measured from polished cross-sections of several composites), $t$ is the average specimen thickness, and epmm is the number of tow ends per mm, and subscripts 0 and 90 refer to the orthogonal directions

The fraction of the interphase material, $f_{i}$, was determined as follows:

$$
f_{i}=\frac{f_{f} m_{i} \rho_{f}}{m_{f} \rho_{i}}
$$

where $m_{f}$ is the mass of the fiber preform before tooling, $m_{i}$ is the mass of the interphase by subtracting the mass of the interphase coated preform from the fiber-only preform mass, and $\rho_{f}$ and $\rho_{i}$ are the densities of the fiber $(2.71 \mathrm{~g} / \mathrm{cc}$ for Hi-Nicalon and $3.05 \mathrm{~g} / \mathrm{cc}$ for Sylramic-iBN) and interphase, respectively. The density of the interphase was assumed to be $1.5 \mathrm{~g} / \mathrm{cc}$ for BN [14] and C. This value may be in error; however, $f_{i}$ is relatively insensitive to the analysis below. The CVI SiC volume was then determined as follows:

$$
V_{S i C}=\frac{V_{\text {sppc }}}{\rho_{\text {SiC }}}\left(\rho_{\text {spec }}-\rho_{f} f_{f}-\rho_{i} f_{i}\right)
$$

where $V_{\text {spec }}$ is the specimen volume, $\rho_{\text {spec }}$ is the specimen density, and $\rho_{S i C}$ is the density of CVI SiC $(3.2 \mathrm{~g} / \mathrm{cc})$. The volume fraction of $\mathrm{SiC}$ matrix, $f_{S i C}$, is then simply $V_{S i C} V_{\text {spec }}$. Finally, the average total fraction of porosity for each specimen could be estimated from the constituent volume fractions: 


$$
f_{p}=1-f_{f}-f_{i}-f_{S i C}
$$

The constituent fractions are listed in Table I.

Room temperature tensile testing was performed using a universal-testing machine (Instron 8562, Instron Ltd., Canton, Mass.) and strain was measured with a clipon extensometer (2.5\% maximum strain range over a $25.4 \mathrm{~mm}$ gage length). For some of the tensile tests, three wide-band acoustic emission (AE) sensors were attached to the specimen, which is described in the companion paper [9]. Specimens were either tested monotonically to failure or were loaded, unloaded, and reloaded at a higher load until failure occurred. The loading rate was $2 \mathrm{kN} / \mathrm{min}$ for the thin specimens, $4 \mathrm{kN} / \mathrm{min}$ for standard specimens, and $10 \mathrm{kN} / \mathrm{min}$ for the thick specimens.

\section{RESULTS}

The composites differ considerably in numbers of plies ( 1 to 36$)$, thickness (0.38 to $10.6 \mathrm{~mm}$ ), and constituent content (Table I). Most notably, $f_{S i C}$ varied by nearly a factor of two and $f_{p}$ varied by nearly a factor of three for the Hi-Nicalon composites. There was also significant variation in $f_{f}$ and some composites fabricated with a carbon interphase for each fiber-type had significantly higher interphase content than the other specimens (Table I).

\section{Microstructure}

Some of the composite microstructures are shown in Figure 2 for HN composites (a-g) and SYL-iBN composites (f-i). Longitudinal sections refer to sections cut and polished along the length of the tensile specimen, whereas the cross section (Figure 2c) refers to the section cut perpendicular to the length of the tensile specimen. The microstructure differs considerably. For the thick specimens (Figure 2d), the exterior plies have a high CVI SiC content whereas the inner plies have larger unfilled regions, typical of preferential $\mathrm{SiC}$ deposition. For the epoxy-infiltrated high-porosity specimens (Figure 2e), the structure is very open. Note how nearly all the coated tows are separate from one another. Noted in Figure $2 \mathrm{a}$ is the $0^{\circ}$ minicomposite, i.e., the region of fiber, interphase, and CVI SiC matrix oriented in the loading direction, and the $90^{\circ}$ 
minicomposite, i.e., the region of fiber, interphase, and CVI SiC matrix oriented perpendicular to the loading direction. This will become important later in the analysis. Also, the effect of fiber-type results in different tow sizes which is a product of the weave, compaction of the ply lay-up by the manufacturer, total fiber count and fiber diameter. The cross-sectional area of fibers in a Hi-Nicalon tow is about $22.5 \%$ greater than the Sylramic-iBN tow. Note also that some axially-oriented porosity exists within the tows.

\section{$\underline{\text { Stress-Strain Behavior and Ultimate Failure }}$}

Room-temperature stress-strain curves obtained by tensile loading along the fiber orthogonal directions are shown in Figure 3 for the different composite systems. As expected, the composites with the lowest porosities had relatively high elastic moduli, whereas the specimens with the highest porosities (epoxy-infiltrated and thin panels) had lower elastic moduli. There was also much variation in non-linear stress-strain behavior and ultimate tensile strength which will be discussed and analyzed in the companion paper [9].

\section{Elastic Modulus and Speed of Sound of Undamaged Composites}

The effect of constituent content on elastic modulus was analyzed for a variety of constituents and physical parameters. On an empirical basis, composite modulus proved to exhibit the best correlation with composite density (Figure 4). There appears to be two regions, a region of higher density where there is a strong relationship between density and $E$ and a lower density region where there is a mild relationship between density and $E$.

The speed of sound of each specimen was used as a check to the measurements of $E$ and $\rho$. Sound waves were created by pencil lead-breaks or by the matrix microfractures that occur near or in the grips at very low loads [9]. The speed of sound could be determined from the difference in time of arrival of the first peak of the relatively nondispersive extensional wave [15]. Figure 5 shows a plot of speed of sound versus

$(E / \rho)^{1 / 2}$ for a number of monolithic materials and the composites tested in this study. Note that under plane strain behavior, it would be proper to compare the measured elastic 
moduli with $\left(E /\left[\rho\left(1-v^{2}\right)\right]\right)^{1 / 2}$, where $v$ is Poisson's ratio. However, $v$ was not known for the composites and was assumed to have a minor affect on the analysis since $v$ would be $\sim 0.2 \pm 0.1$. The speeds of sound of the monoliths fall just below a line of direct proportion, due to the absence of $v$ in the comparison. The speeds of sound of the composites fall near the same line indicating a good correlation of measured elastic modulus and density.

\section{Modeling Elastic Modulus: The Role of the $90^{\circ}$ Minicomposite}

Similar to reference 6 , the entire composite can be considered to consist of $0^{\circ}$ (stressed direction) and $90^{\circ}$ (perpendicular to stress direction) oriented fiber-interphaseCVI SiC minicomposites. In this construction, the minicomposite is not necessarily a uniform mixture, unlike 0/90 laminate composites [16-17], but may contain two distinct regions: an inner region consisting of a mixture of fibers, interphase coating, CVI SiC and inner-tow porosity surrounded by an outer "shell" of CVI SiC if a sufficient amount of $\mathrm{SiC}$ is infiltrated to fill the inner region (Figure $6 \mathrm{a}$ and $\mathrm{b}$ ). In addition, there are typically large open pores associated with weave crossover points and depends on the degree of "nesting" achieved after ply stacking and pressing.

The difficulty in modeling the elastic modulus of woven composites comes with the treatment of the $90^{\circ}$ minicomposites and the network of open porosity. The large open porosity in composites is sometimes associated with $0^{\circ}$ minicomposites and can be considered in parallel to the loading direction; however, some large pores are associated with the $90^{\circ}$ minicomposites and would appear to be in series in a given ply. The large pores associated with the $90^{\circ}$ plies would increase as epcm decreases for the $90^{\circ}$ orientation. On the other hand, nesting, ply compaction, and the registry of ply lay-up can minimize the porosity within and between plies. Also, if the porosity is on average welldistributed in a cross-section and good transfer of load exists between $0^{\circ}$ and $90^{\circ}$ minicomposites over a critical length scale in the loading direction, it is possible that all of the open porosity can be treated in parallel. The approach here will be to determine in general the degree of load carried by the $90^{\circ}$ minicomposites assuming that all of the large open porosity acts in parallel under load. Then a model for the elastic modulus of 
the $90^{\circ}$ minicomposites will be developed based on constituent content in order to predict the composite elastic modulus for the different CVI SiC composites studied.

First it is assumed that all of the condensed phases in the composite are associated with $0^{\circ}$ and $90^{\circ}$ oriented tow minicomposites (Figure 6a). To determine the degree of load-carrying contribution for the $90^{\circ}$ minicomposites, it is first assumed that three elements, $0^{\circ}$ minicomposites, $90^{\circ}$ minicomposites, and open porosity, act in parallel and can therefore be described by the Rule of Mixtures:

$$
A_{c} \varepsilon_{c} E_{c}=A_{0} \varepsilon_{0} E_{0}{ }^{*}+A_{90} \varepsilon_{90} E_{90}{ }^{*}+A_{\text {open-por }} \varepsilon_{\text {open-por }} E_{\text {open-por }}
$$

Where $A$ is area, $\varepsilon$ is strain, $E^{*}$ is the elastic modulus of the $0^{\circ}$ and $90^{\circ}$ minicomposites and subscripts "c" and "open-por" refer to composite and open porosity, respectively. The total porosity (Table I) is the sum of the open porosity and the inner porosity (the porosity contained within the minicomposite estimated here to be $\sim 5 \%$ of the composite volume). $E_{90}{ }^{*}$ and $E_{90}{ }^{*}$ are considered to be the effective moduli of the entire $0^{\circ}$ and $90^{\circ}$ minicomposites as depicted in Figure $6 \mathrm{a} . E_{90}{ }^{*}$ then describes the load-carrying ability of the $90^{\circ}$ minicomposite.

Assuming equivalence of the strain terms and $E_{\text {open-por }}=0$, the volume fraction of minicomposites is the area of the minicomposites divided by the area of the composite, and solving for $E_{c}$ reduces Equation 5 to:

$$
E_{c}=f_{0} E_{0}{ }^{*}+f_{90} E_{90}{ }^{*}
$$

Where $f_{0}$ and $f_{90}$ are the volume fractions of $0^{\circ}$ and $90^{\circ}$ oriented minicomposites and can be represented by:

$$
\begin{aligned}
& f_{0}=l_{0}\left(f_{f}+f_{i}+f_{\text {SiC }}+f_{\text {inner-por }}\right) \\
& f_{90}=\left(1-l_{0}\right)\left(f_{f}+f_{i}+f_{\text {SiC }}+f_{\text {inner-por }}\right)
\end{aligned}
$$


where $f_{\text {inner-por }}$ is the total fraction of porosity in the inner region of a minicomposite $(\sim$ $0.05)$ and $l_{0}$ is the ratio of fibers oriented in the loading direction:

$$
l_{0}=\frac{e p c m_{0}}{e p c m_{0}+e p c m_{90}}
$$

For a balanced weave, $l_{0}=0.5$.

$E_{0}{ }^{*}$ can simply be determined from Rule of Mixtures of the constituent content of the $0^{\circ}$ minicomposites:

$$
E_{0}^{*}=\frac{l_{0}\left(f_{f} E_{f}+f_{i} E_{i}+f_{S i C} E_{S i C}\right)}{f_{0}}
$$

Where $E_{f}=380 \mathrm{GPa}$ for Sylramic-iBN and $280 \mathrm{GPa}$ for Hi-Nicalon, $E_{S i C}=425 \mathrm{GPa}$ for $\mathrm{CVI} \mathrm{SiC}$, and $E_{i}=23 \mathrm{GPa}$ (see below). Then, $\mathrm{E}_{90}{ }^{*}$ can be backed out from equation 6:

$$
E_{90}^{*}=\frac{\left(E_{c}-f_{0} E_{0}^{*}\right)}{f_{90}}
$$

Figure 7 shows the relative load carrying ability of the $90^{\circ}$ minicomposites as plotted against density. There is a striking demarcation between high density and low density composites. The higher density composites exhibit significant load-sharing in the $90^{\circ}$ minicomposites whereas in the low density minicomposites, the $90^{\circ}$ minicomposites exhibit little or no actual contribution to load-sharing. Physically this implies that $a$ sufficient amount of CVI SiC is necessary to insure good interaction or strong bonding between adjacent plies so that the $90^{\circ}$ are loaded. This explains why there was little effect of density on $E_{c}$ for the low density composites (Figure 4). Practically then, for low density composites, it can be assumed that the $90^{\circ}$ minicomposites do not share the load:

$$
E_{c}\left(\text { low density) }=f_{0} E_{0}{ }^{*}\right.
$$




\section{Modeling Elastic Modulus: High Density Composites}

For higher density composites it is obvious that the $90^{\circ}$ minicomposites carried significant load. The minicomposite consists of the two regions mentioned above: the inner region of the minicomposite and the outer region of CVI SiC (Figure 6). The inner region of the $90^{\circ}$ minicomposite is the most difficult entity to model. One unknown quantity is the elastic modulus of the low-temperature deposited CVI BN. The composite specimens where there was very little porosity in between $90^{\circ}$ minicomposites, the SyliBN composites oriented with the $5.5 \mathrm{epcm}$ in the $0^{\circ}$ direction (Figure $2 \mathrm{~h}$ ), was used to "back out" the elastic modulus of the inner region of the $90^{\circ}$ minicomposite and to estimate $E_{i}$. For this case, nearly all of the porosity is aligned axially (Figure $2 \mathrm{~g}$ would correspond to a cross-section where the $5.5 \mathrm{epcm}$ orientated tows are loaded). Also, nearly all of the CVI SiC that is infiltrated outside of the inner region of the minicomposites is well situated with the $0^{\circ}$ tows or the surface of the composite enabling good load transfer to this portion of CVI SiC and would fulfill the requirement that the CVI SiC outside of the inner region of the minicomposite operates in parallel. Therefore, the "outer SiC" corresponding to $0^{\circ}$ minicomposites, $90^{\circ}$ minicomposites, and the surface of the composites will be treated as one entity and the "inner region" of the minicomposites will be modeled separately. Since the inner region of the $0^{\circ}$ minicomposites, the outer-SiC, and the open porosity were all aligned in parallel to the loading direction, the elastic modulus of the inner region of the $90^{\circ}$ minicomposites could be determined from rule of mixtures:

$$
E_{\text {inner } 90}=\frac{E_{c}-f_{\text {inner } 0} E_{\text {inner } 0}-f_{\text {outerSiC }} E_{S i C}}{f_{\text {inner } 90}}
$$

where "inner" refers to the inner region of a minicomposite. The fractions of the inner regions of the minicomposite are simply:

$$
\begin{aligned}
& f_{\text {inner } 0}=f_{f \text {-inner }}^{0}+f_{\text {i-inner }}^{0}+f_{\text {SiC-inner }}^{0}+f_{\text {porosity-inner }}^{0} \\
& f_{\text {inner } 90}=f_{f \text {-inner }}^{90}+f_{i \text {-inner }}^{90}+f_{\text {SiC-inner }}^{90}+f_{\text {porosity-inner }}^{90}
\end{aligned}
$$

For a balanced composite, with the same tow size in the orthogonal directions, $\mathrm{f}_{\mathrm{inner} 0}$ and $\mathrm{f}_{\text {inner} 90}$ would be equivalent. Since all of the fibers and the interphase coating are contained in the inner regions of the minicomposite: 


$$
\begin{aligned}
& f_{j-\text { inner }}^{0}=l_{0} f_{j} \\
& f_{j \text {-inner }}^{90}=\left(1-l_{0}\right) f_{j}
\end{aligned}
$$

where subscript $j$ pertains to $f, i$, and porosity-inner. $f_{\text {SiC-inner }}$ can only be determined if $f_{\text {inner }}$ is known. This depends on the volume (area) of the tow, which may differ for different architectures. The two dimensions, height (2a) and width (2b), of the inner regions of the tows (Figure 6b) were measured for representative specimens from each panel for both orthogonal directions (Table II). There was essentially no difference in tow size of the orthogonal minicomposites for a given balanced panel. There was very little difference in tow dimensions for different panels with balanced architectures and the same fiber types. There were also minor differences measured for the two orthogonal directions in the unbalanced composites. The actual shape of a cross-section of a tow varies between an ellipse and a rectangle. The latter was chosen here to describe the tow cross-section:

$$
\begin{aligned}
& f_{\text {inner }}^{0}=\frac{A_{\text {inner }}^{0}}{A_{\text {tot }}}=\frac{\text { epmm }_{0} 2 a_{0} 2 b_{0} N_{p l y}}{t} \\
& f_{\text {inner }}^{90}=\frac{A_{\text {inner }}^{90}}{A_{\text {tot }}}=\frac{e p m m_{90} 2 a_{90} 2 b_{90} N_{p l y}}{t}
\end{aligned}
$$

where $A_{\text {tot }}$ is the cross-sectional area of the composite. $f_{\text {SiC-inner }}$ can then be determined from Equations $13 \mathrm{a}$ and $\mathrm{b}$ for the $0^{\circ}$ and $90^{\circ}$ orientations, respectively. $\mathrm{E}_{\text {innerSic }}^{\mathrm{o}}$ can be determined from the rule of mixtures and the fraction of outer-SiC as follows:

$$
f_{\text {outerSiC }}=f_{\text {SiC }}+f_{\text {SiC-inner }}^{0}+f_{\text {SiC-inner }}^{90}
$$

Equation 12 was solved for the Sylramic-iBN composite specimens where the 5.5 epcm tows were aligned in the loading direction. $E_{\text {inner } 90}$ was found to be $140 \pm 5 \mathrm{GPa}$ for two specimens.

Next, the inner $90^{\circ}$ elastic modulus can be modeled for the unbalanced Syl-iBN composite oriented with the 5.5 epcm tows in the loading direction. In reference 6 , it was assumed that the fibers in the $90^{\circ}$ minicomposite act as pores due to poor load transfer through the weak interface. For the composites of this study, it is evident that the $90^{\circ}$ minicomposites do carry significant loads (Figure 7). If there is enough load transfer within the inner region of the $90^{\circ}$ minicomposite, the elastic modulus must be accounted 
for. However, $E_{i}$ of $\mathrm{BN}$ deposited at low temperatures is not well understood. In another study, it was assumed that the elastic modulus of the nanocrystalline randomly oriented $\mathrm{BN}$ was $62 \mathrm{GPa}$ [14]. The elastic modulus of low temperature derived $\mathrm{BN}$ ranges from 10 to $200 \mathrm{GPa}$ [18-20] depending on orientation and crystallinity. Since $E_{\text {inner } 90}$ was estimated for the composites with the $5.5 \mathrm{epcm}$ tows oriented in the loading direction, a simple Reuss element (Equation 17) was used to model $E_{i n n 90}$ from which $E_{i}$ could be backed out. The best fit $E_{i}$ equaled $23 \mathrm{GPa}$. This value corresponds well with the elastic modulus of BN (20 GPa) in similar composites measured by nanoindentation [21].

$$
E_{\text {inner } 90}=\left(\frac{f_{\text {inner }-i}}{E_{i}}+\frac{f_{\text {inner }-f}}{E_{f}}+\frac{f_{\text {inner } S i C}}{E_{S i C}}\right)^{-1}
$$

Finally, the same approach and assumptions $\left(0^{\circ}\right.$ inner minicomposite, outer $\mathrm{SiC}$, macroporosity, and $90^{\circ}$ inner minicomposite all act in parallel) were applied to model the elastic modulus of all the higher density composites. Two extremes were modeled for $E_{\text {inner } 90}$. The high stiffness extreme used Equation 17 to estimate $E_{\text {inner } 90}$ with $E_{i}$ assumed to be $23 \mathrm{GPa}$. The low stiffness extreme assumed $E_{\text {inner } 90}=0$, i.e., poor load-transfer or fiber-matrix decoupling within the inner region of the minicomposite. The Rule of Mixtures relationship, Equation 12 (solved for $E_{c}$ ), was used to determine $E_{c}$. Figure 8 plots the measured $E_{c}$ vs the predicted $E_{c}$ for the Sylramic-iBN and Hi-Nicalon composite systems. For the lower density Hi-Nicalon composites, Equation 11 was used to predict $E_{c}$. Table III lists the measured and estimated moduli for each specimen.

There is excellent agreement between predicted and measured $E_{c}$ for the Sylramic-iBN composites regardless of interphase or orientation when using the Reuss model to describe $E_{\text {inner } 90}$. The Hi-Nicalon composites are in good agreement for the Reuss model; however, the predicted $E_{c}$ tended to overestimate the measured value. The lower extreme prediction, $E_{\text {inner } 90}=0$, underestimated the measured $E_{c}$ for all the higher density composites except for the 8 ply carbon interphase Hi-Nicalon CVI SiC.

\section{DISCUSSION:}

The elastic modulus of the CVI SiC matrix composites was predicted by applying simple Rule of Mixture techniques for a wide range of constituent content, ply lay up, fiber-type, woven fiber tows per length, balanced weave and unbalanced weave. The 
good correlation between prediction and measured values appears to vindicate the simple assumptions that went into the analysis. This approach should also provide designers with simple, yet fairly robust, relationships for modeling the elastic modulus of $2 \mathrm{D}$ woven CVI SiC matrix composites in the orthogonal direction. The entire analysis requires only the knowledge of the fractional contents, $f_{f}, f_{i}$, and $f_{S i C}$, of the condensed phases and the general shape, balance, and size of the tows. This could easily be incorporated into modeling the local stiffness of a component if the local constituent contents and tow shape of a complex component are known from process models, microstructural evaluation, and/or NDE techniques where local processing variation may occur due to nonuniform infiltration of interphase or more likely CVI SiC. It should also be noted that the stiffness in off-axis directions measured by others [4] and determined by the speed of sound as a function of orientation [22] for panels of similar high density composites show only a slightly lower modulus $(\sim 5 \%)$ than the orthogonal directions. This is presumably due to the fact that this property is dominated by the CVI SiC. Therefore, once $E$ is known in the orthogonal directions, a slight "knock down" modification can be made as a function of orientation.

The demarcation between low and high density that dictated the change in elastic modulus was not determined absolutely in this study. It was found that the stiffness of composites less than $\sim 2.0 \mathrm{~g} / \mathrm{cc}$ was controlled by the $0^{\circ}$ minicomposites whereas composites greater than $\sim 2.3 \mathrm{~g} / \mathrm{cc}$ had significant load-shared by the $90^{\circ}$ minicomposites. This result points to a lack of interaction between $90^{\circ}$ minicomposites with $0^{\circ}$ minicomposites at the lower densities probably due to low CVI SiC contents. It may also be due in part to large pores acting more in series rather than in parallel when loaded. It is not known whether there is a clear demarcation between these two regions or whether there will be a gradual transition from one to the other.

There was greater variability in the predicted elastic moduli for Hi-Nicalon composites. The largest overestimate of the predicted $E_{c}$ for the high-density Hi-Nicalon composites was never greater than $11 \%$ of the measured $E_{c}$ value. The reason for this is unknown. There were differences in interphase compositions; however, the interphase composition did not appear to affect predictability. The degree of bonding between HiNicalon fibers and the interphase may be weaker than that for the Sylramic-iBN. The Hi- 
Nicalon fiber has a smooth sometimes carbonaceous surface mating the interphase. This may lead to poorer bonding and load-sharing when loaded transversely. The SylramiciBN has a rough surface where the outer $\sim 100 \mu \mathrm{m}$ of the fiber was converted to a crystalline BN which would be expected to provide better bonding and load transfer. It should be noted that Sylramic-iBN composites fabricated with an already debonded interphase/matrix interface (outside debonding) had a significantly lower $E_{c}$ when compared to composites of the same constituent content that did not show the same degree of processing-induced debonding [23].

It is evident that significant load is carried by the inner regions of the $90^{\circ}$ minicomposites when good interaction between $90^{\circ}$ and $0^{\circ}$ is achieved with high enough $\mathrm{CVI} \mathrm{SiC}$ contents. On average, $E_{\text {inner } 90}$ for typical $\mathrm{HN} 90^{\circ}$ minicomposites (excluding the HN 8PLY C interphase composite) was approximately $175 \mathrm{GPa}$ and for typical SylramiciBN $90^{\circ}$ minicomposites (excluding the $7.9 \mathrm{epcm}$ Syl-iBN C interphase composite) was approximately $150 \mathrm{GPa}$. There was some minor variation from panel to panel due to minor differences in constituent fraction content (Table III). Note that for the thick interphase composites, HN 8PLY(C) and 7.9 epcm Syl-iBN (C) composite specimens, $E_{\text {innergo }}$ is significantly lower because very little CVI SiC actually penetrates the inner region of the minicomposite. For the HN 8PLY(C) composite, the low modulus for $E_{\text {inner } 90}$ still resulted in an overestimate of the measured $E_{c}$. For that case, $E_{\text {inner } 90}=0$ was the best predictor. For the 7.9 epcm Syl-iBN (C), the low modulus for $E_{\text {inner } 90}$ worked very well in predicting $E_{c}$.

Finally, with a model for $E_{c}$, the full linear and non-linear behavior of 2D woven CVI SiC composites can be modeled. It will be shown in the companion paper [9] that the matrix crack density for the high density composite can be simply modeled by the stress in the CVI $\mathrm{SiC}$ as determined by local elastic strain which necessitates $E_{c}$ to be known for a given system. It is also believed that this approach serves as a basis for modeling $E_{c}$ in dense melt-infiltrated composites by filling in most of the porosity with $\mathrm{Si}$ and $\mathrm{SiC}$. This will be the focus of a future study.

\section{CONCLUSION}


The elastic modulus of woven $\mathrm{SiC}$ fiber-reinforced, CVI SiC matrix composites stressed in one of the orthogonal directions could effectively be modeled by assuming that the basic structural elements of the composites are the $0^{\circ}$ oriented (loading direction) and $90^{\circ}$ oriented fiber, interphase, and CVI SiC minicomposites. This was accomplished for a wide variation of constituent content, fiber-type, ply lay-up, and interphase content. The effect of constituent content on elastic modus not only depends on the relative amounts of constituents, but also on the effectiveness of the structure, i.e., $90^{\circ}$ minicomposites, to carry load. Lower density composites have very little load-carrying contribution from $90^{\circ}$ minicomposites when loaded in the $0^{\circ}$ direction whereas significant load was carried by the $90^{\circ}$ minicomposites for higher density composites. The treatment of the inner region of the $90^{\circ}$ minicomposite as a series element (Reuss model) of the three condensed phases proved to be most effective towards predicting the elastic modulus of the higher density composites. It is concluded that this represents a very simple yet robust approach to modeling the stiffness of 2D woven $\mathrm{SiC}$ fiber-reinforced $\mathrm{SiC}$ matrix composites when loaded in the orthogonal direction that can be implemented by designers rather easily.

\section{REFERENCES}

1. R. Naslain, "Design, preparation and properties of non-oxide CMCs for application in engines and nuclear reactors: an overview" Comp. Sci. Tech., 64 (2004) 155-170.

2. Guillaumat, L. and Lamon, J., "Multi-fissuration de Composites SiC/SiC," in

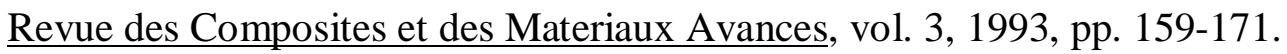

3. Guillaumat, L. and Lamon, J., "Probabilistic-Statistical Simulation of the NonLinear Mechanical Behavior of a Woven SiC/SiC Composite," Composites Science and Technology, Vol. 56, 1996, pp. 803-808.

4. X. Aubard, J. Lamon, and O. Allix, "Model of the Nonlinear Mechanical Behavior of 2D SiC-SiC Chemical Vapor Infiltration Composites," J. Am. Ceram. Soc., Vol. 77, No. 8, (1994) pp. 2118-26 
5. Pluvinage, P., Parvizi-Majidi, A., and Chou, T.W., "Damage Characterization of Two-Dimensional woven and Three-Dimensional Braided SiC-SiC Composites," Journal of Materials Science, Vol. 31, 1996, 232-241.

6. J. Lamon, B. Thommeret, and C. Percevault, "Probabilistic-statistical Approach to Matrix Damage and Stress-Strain Behavior of 2-D Woven SiC/SiC Ceramic Matrix Composites,” J. European Ceramic Society, 18 (1998) 1797-1808

7. J. Chevalier, M. Huger, D. Fargeot, and C. Gault, "Ultrasonic Investigation of the Time-dependent Damage in a 2D SiC/SiC Composite Under Static Loading," J. European Ceramic Society, 18 (1998) 1857-1867

8. J. Lamon, "A Micromechanics-based Approach to the Mechanical Behavior of Brittle-Matrix Composites,” Comp. Sci. Tech., 61 (2001) 2259-2272

9. G. Morscher, M. Singh, J. Kiser, R. Bhatt, and M. Freedman, "Stress-Dependent Matrix Cracking in CVI SiC Composites", submitted to Comp. Sci. Tech.

10. R.T. Bhatt, Y.L. Chen, and G.N. Morscher, "Microstructure and tensile properties of BN/SiC coated Hi-Nicalon, and Sylramic SiC fiber performs," J. Mater. Sci., Vol. 37, pp. 3991-3998 (2002)

11. D. Brewer, "HSR/EPM Combustor Materials Development Program”, Mater. Sci. Eng. A, Vol. A261 (1999) pp. 284-291.

12. G.N. Morscher and M. Singh, Thermo-Mechanical Performance of Multilayer C and SiC Fiber-Reinforced, CVI SiC Matrix Composites", presented at $28^{\text {th }}$ International Cocoa Beach Conference on Advanced Ceramics and Composites (2004)

13. H.M. Yun and J.A. DiCarlo, "Comparison of the Tensile, Creep, and Rupture Strength Properties of Stoichiometric SiC Fibers,” Cer. Eng. Sci. Proc., 20 [3] 259-272 (1999)

14. S.K. Mital, M. Tong, P.L.N. Murthy, and J.A. DiCarlo, "Micromechanics-Based Modeling of Thermal and Mechanical Properties of an Advanced SiC/SiC Composite Material,” NASA/TM - 97-206295 December, 1997

15. G.N. Morscher, Comp. Sci. Tech., "Stress-Dependent Matrix Cracking in 2D Woven SiC-fiber Reinforced Melt-Infiltrated SiC Matrix Composites,” Vol. 59, No. 5 (1999) pp. 687-697 
16. D.S. Beyerle, M. Spearing, and A.G. Evans, "Damage Mechanisms and the Mechanical Properties of a Laminated 0/90 Ceramic/Matrix Composite," J. Am. Ceram. Soc., 75 [12] 3321-30 (1992)

17. C. Xia, R.R. Carr, and J.W. Hutchinson, "Transverse Cracking in Fiber Reinforced Brittle Matrix Cross-Ply Laminates,” Acta Metall. Mater., 41 [3] 2365-76 (1993)

18. J. Vilcarromero, M.N.P Carreno, I.Pereyra, "Mechanical properties of boron nitride thin films obtained by RF-PECVD at low temperatures," Thin Solid films 373 (2000) 273-276

19. J-G Kho, K-T Moon, J-H Kim, and D-P Kim, "Properties of Boron Nitride (BxNy) Films Produced by the Spin-Coating Process of Polyborazine," J. Am. Ceram. Soc., 83 [11] 2681-2683 (2000)

20. H.Vincent, F. Chassagneux, C. Vincent, B. Bonnetot, M.P. Berthet, A. Vuillermoz, and J. Bouix, "Microtexture and structure of boron nitride fibres by transmission electron microscopy, X-ray diffraction, photoelectron spectroscopy, and Raman scattering," Mater. Sci. Eng. A340 (2003) 181-192

21. G. Ojard and Y. Gowayed, presented at Advanced Ceramics and Composites Meeting, Cocoa Beach, FL, January $24^{\text {th }}, 2005$

22. G. N. Morscher, unpublished research.

23. G.N. Morscher, H.M. Yun, J.A. DiCarlo, and L. Thomas-Ogbuji, "Effect of a Boron Nitride that Debonds Between the Interphase and the Matrix in $\mathrm{SiC} / \mathrm{SiC}$ Composites," J. Am. Ceram. Soc., 87 [1] 104-12 (2004) 
Table I: Physical Properties of Composite Specimens

\begin{tabular}{|c|c|c|c|c|c|c|c|}
\hline $\begin{array}{c}\text { Specimen (interphase) } \\
\text { \{no. specimens }\end{array}$ & Weave & $\begin{array}{l}\text { Specimen } \\
\text { shape }\end{array}$ & $\begin{array}{c}\mathbf{t}, \\
\mathbf{m m}\end{array}$ & $\mathbf{f}_{\mathrm{f}}$ & $\mathbf{f}_{\mathrm{i}}$ & $\mathbf{f}_{\mathrm{SiC}}$ & $\mathbf{f}_{\mathrm{p}}$ \\
\hline \multicolumn{8}{|c|}{ Hi-Nicalon Composites } \\
\hline \multicolumn{8}{|l|}{ Standard 8 Ply Panels } \\
\hline $8 \mathrm{Ply}(\mathrm{C})\{2\}$ & $8 \mathrm{HS}$ & $\operatorname{dog}-A^{a}$ & 2.84 & 0.28 & 0.13 & 0.44 & 0.15 \\
\hline 8 Ply (BN1) $\{2\}$ & $8 \mathrm{HS}$ & $\operatorname{dog}-A$ & 2.37 & 0.37 & 0.05 & 0.41 & 0.17 \\
\hline 8 Ply (BN2) $\{2\}$ & $5 \mathrm{HS}$ & dog- $B^{b}$ & 2.53 & 0.31 & 0.06 & 0.48 & 0.15 \\
\hline 8 Ply (BN3) $\{1\}$ & $5 \mathrm{HS}$ & dog-B & 2.14 & 0.33 & 0.05 & 0.47 & 0.15 \\
\hline \multicolumn{8}{|l|}{ Standard Thick Panels } \\
\hline 30 Ply (C) $\{1\}$ & AS & dog-B & 8.68 & 0.34 & 0.04 & 0.45 & 0.17 \\
\hline 36 Ply (C) $\{1\}$ & $5 \mathrm{HS}$ & dog-B & 10.56 & 0.34 & 0.04 & 0.43 & 0.19 \\
\hline \multicolumn{8}{|l|}{ Thin Panels } \\
\hline 1 Ply $(C)\{1\}$ & $5 \mathrm{HS}$ & Straight $^{\mathrm{s}}$ & 0.38 & 0.26 & 0.04 & 0.29 & 0.41 \\
\hline 2 Ply (C) $\{2\}$ & $5 \mathrm{HS}$ & Straight & 0.73 & 0.28 & 0.04 & 0.33 & 0.35 \\
\hline 3 Ply (C) $\{2\}$ & $5 \mathrm{HS}$ & Straight & 0.92 & 0.32 & 0.04 & 0.35 & 0.29 \\
\hline \multicolumn{8}{|l|}{ Epoxy Iniltrated Panels } \\
\hline E8Ply-5HS(BN1) $\{1\}$ & $5 \mathrm{HS}$ & dog-B & 2.45 & 0.32 & 0.05 & 0.25 & 0.38 \\
\hline E8Ply-5H & $5 \mathrm{HS}$ & dog-B & 2.45 & 0.32 & 0.05 & 0.27 & 0.35 \\
\hline E8Ply-8HS(BN) $\{1\}$ & $8 \mathrm{HS}$ & dog-B & 2.37 & 0.33 & 0.05 & 0.29 & 0.33 \\
\hline \multicolumn{8}{|c|}{ Sylramic-iBN Composites (Standard 8 Ply Panels) } \\
\hline 8 Ply 7.9 epcm (1) $\{1\}$ & $5 \mathrm{HS}$ & $\operatorname{dog}-A$ & 2.18 & 0.363 & 0.071 & 0.377 & 0.189 \\
\hline 8 Ply 7.9 epcm (2) $\{1\}$ & $5 \mathrm{HS}$ & $\operatorname{dog}-A$ & 2.17 & 0.365 & 0.069 & 0.387 & 0.179 \\
\hline 8 Ply 7.9 epcm (3) \}1\} & $5 \mathrm{HS}$ & $\operatorname{dog}-A$ & 2.19 & 0.361 & 0.070 & 0.443 & 0.126 \\
\hline 8 Ply 7.9 epcm (C) $\{1\}$ & $5 \mathrm{HS}$ & dog-A & 2.38 & 0.332 & 0.229 & 0.346 & 0.093 \\
\hline 8 Ply Unbalanced $\{4\}$ & $5 \mathrm{HS}$ & dog-A & 2.24 & 0.335 & 0.069 & 0.464 & 0.132 \\
\hline
\end{tabular}

${ }^{a}$ Dogbone tensile specimen $203 \mathrm{~mm}$ in length, approximately $15.5 \mathrm{~mm}$ in width at grip section and $10.3 \mathrm{~mm}$ in width at gage section

${ }^{\mathrm{b}}$ Dogbone tensile specimen $152 \mathrm{~mm}$ in length, approximately $12.6 \mathrm{~mm}$ in width at grip section and $10.3 \mathrm{~mm}$ in width at gage section

${ }^{\mathrm{s}}$ Straight-sided tensile specimen $152 \mathrm{~mm}$ in length and approximately $12.6 \mathrm{~mm}$ in width throughout. 
Table II: Tow Size and Shape for Representative Composites

\begin{tabular}{|c|c|c|c|c|}
\hline Composite Specimen & Architecture, Fiber-type & $\begin{array}{l}\text { \# of tows } \\
\text { measured }\end{array}$ & $2 a, m m$ & $2 b, \mathrm{~mm}$ \\
\hline HN 8 PLY (BN1) & Standard 8 ply, HN & 30 & $0.13 \pm 0.02$ & $1.15 \pm 0.09$ \\
\hline HN 8 PLY (BN2) & Standard 8 ply, HN & 33 & $0.14 \pm 0.02$ & $1.19 \pm 0.10$ \\
\hline HN 8 PLY (BN3) & Standard 8 ply, HN & 15 & $0.13 \pm 0.02$ & $1.21 \pm 0.10$ \\
\hline HN 8 PLY (C) & Standard 8 ply, HN & 32 & $0.14 \pm 0.02$ & $1.22 \pm 0.20$ \\
\hline E8Ply-8HS(BN) & Epoxy infiltrated 8HS, HN & 23 & $0.14 \pm 0.02$ & $1.17 \pm 0.14$ \\
\hline 3 Ply (C) & Thin (3 Ply), HN & 15 & $0.14 \pm 0.02$ & $1.18 \pm 0.09$ \\
\hline 7.9 epcm Syl-iBN (BN1) & Balanced, Syl-iBN & 32 & $0.11 \pm 0.02$ & $1.04 \pm 0.10$ \\
\hline 7.9 epcm Syl-iBN (BN2) & Balanced, Syl-iBN & -- & $0 . \overline{11} 1^{*}$ & $1.015^{\star}$ \\
\hline 7.9 epcm Syl-iBN (BN3) & Balanced, Syl-iBN & 36 & $0.11 \pm 0.01$ & $0.99 \pm 0.10$ \\
\hline 7.9 epcm Syl-iBN (C) & Balanced, Syl-iBN & 32 & $0.11 \pm 0.01$ & $1.17 \pm 0.10$ \\
\hline 9.4 epcm Syl-iBN (BN) & Unbalanced, Syl-iBN & 63 & $0.11 \pm 0.01$ & $1.13 \pm 0.10$ \\
\hline 5.5 epcm Syl-iBN (BN) & Unbalanced, Syl-iBN & 59 & $0.10 \pm 0.01$ & $1.08 \pm 0.08$ \\
\hline
\end{tabular}

* Average of 7.9 epcm Syl-iBN (BN1) and (BN3) panels were used

Table III: Moduli Measurements and Predictions for High Density Composites

\begin{tabular}{|c|c|c|c|}
\hline $\begin{array}{l}\text { Composite } \\
\text { Specimen }\end{array}$ & $\begin{array}{c}\text { Measured } \\
\text { E}_{c}, \mathrm{GPa}\end{array}$ & $\begin{array}{c}\text { Predicted E90-inner, } \\
\text { GPa }\end{array}$ & $\begin{array}{l}\text { Predicted } E_{c}, \\
\text { GPa }\end{array}$ \\
\hline \multicolumn{4}{|c|}{ Hi-Nicalon Composites } \\
\hline HN 8 PLY (BN1) & 258 & 175 & 261 \\
\hline HN 8 PLY (BN1) & 269 & 175 & 258 \\
\hline HN 8 PLY (BN2) & 243 & 157 & 251 \\
\hline HN 8 PLY (BN2) & 225 & 157 & 253 \\
\hline HN 8 PLY (BN3) & 225 & 180 & 244 \\
\hline HN 8 PLY (C) & 199 & 90 & 226 \\
\hline HN 8 PLY (C) & 195 & 90 & 215 \\
\hline HN 30 Ply (C) & 237 & 194 & 261 \\
\hline HN 36 Ply (C) & 231 & 183 & 250 \\
\hline \multicolumn{4}{|c|}{ Sylramic-iBN Composites } \\
\hline 7.9 epcm Syl-iBN (BN1) & 247 & 153 & 247 \\
\hline 7.9 epcm Syl-iBN (BN2) & 254 & 156 & 253 \\
\hline 7.9 epcm Syl-iBN (BN3) & 278 & 148 & 279 \\
\hline 7.9 epcm Syl-iBN (C) & 230 & 63 & 223 \\
\hline 9.4 epcm Syl-iBN (BN) & 289 & 154 & 293 \\
\hline 9.4 epcm Syl-iBN (BN) & 293 & 154 & 303 \\
\hline 5.5 epcm Syl-iBN (BN) & 260 & 139 & 258 \\
\hline 5.5 epcm Syl-iBN (BN) & 261 & 140 & 263 \\
\hline
\end{tabular}




\section{Approaches to Composite Fabrication}

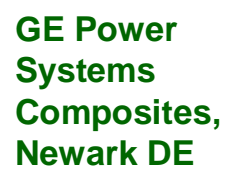

GE Power Systems Composites, Newark DE

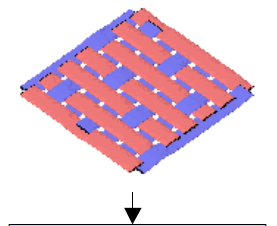

CVI BN or C Infiltration<smiles></smiles>
2D lay-up fixed in tooling

Interphase deposition, then removal from tool

\section{SiC \\ Infiltration}

\section{Dog Bone Tensile Bars Machined

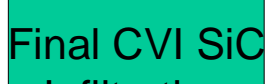 \\ Infiltration}

8, 30, \& 36 ply Standard Panels

(a)

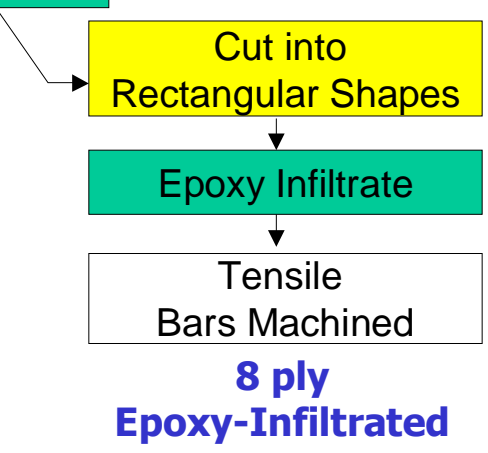

(b)

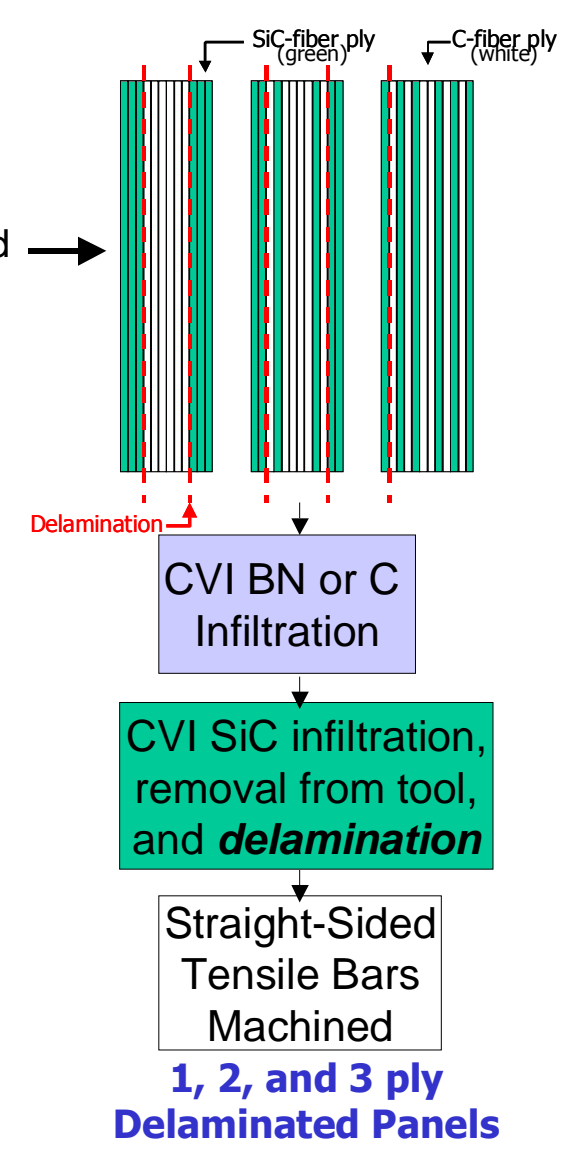

(c)

Figure 1: Approaches to composite fabrication 


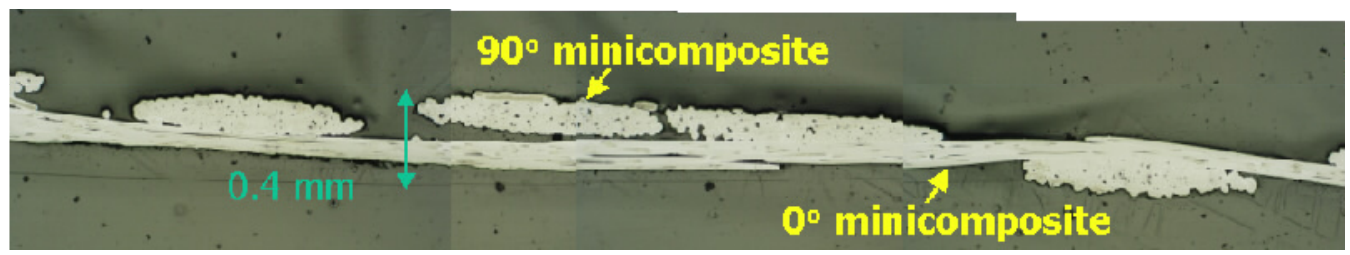

(a) HN 1 Ply Longitudinal Section

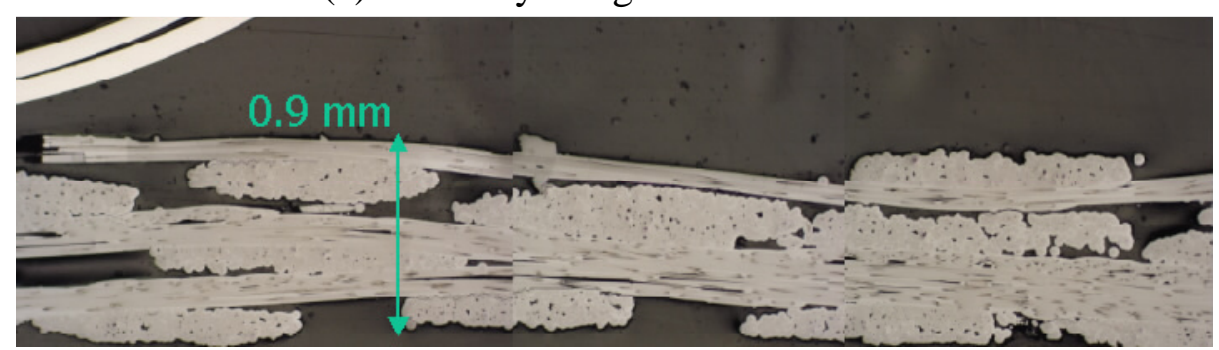

(b) HN 3 Ply Longitudinal Section

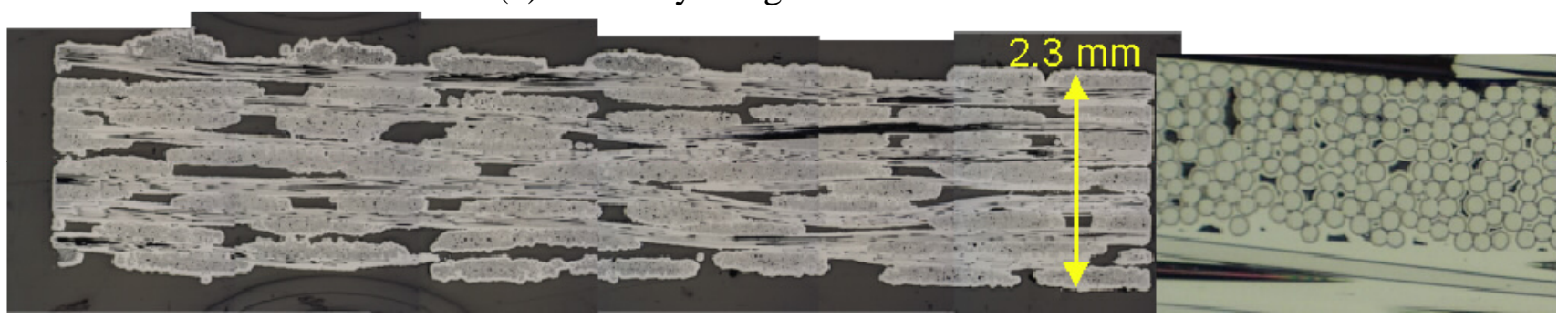

(c) HN 8 Ply (BN1) Cross-Section

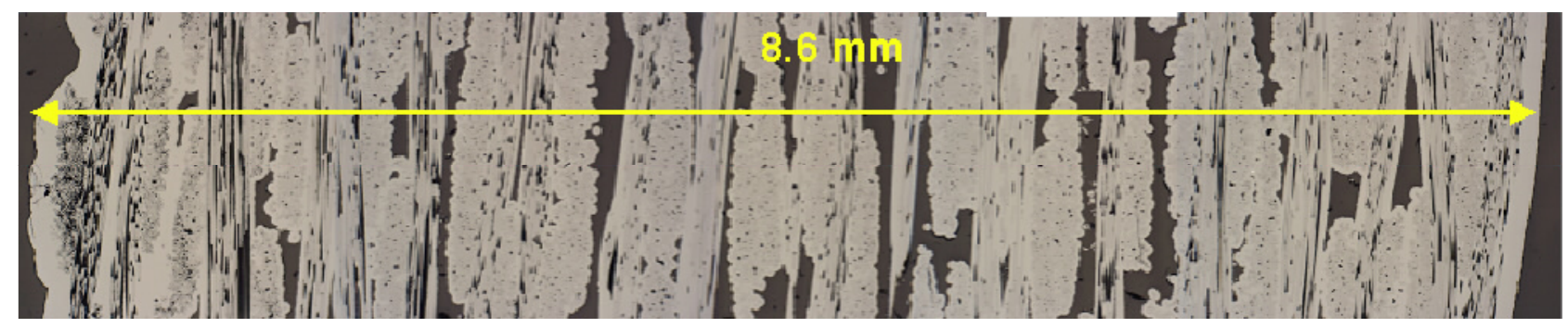

(d) HN 30 Ply Longitudinal Section
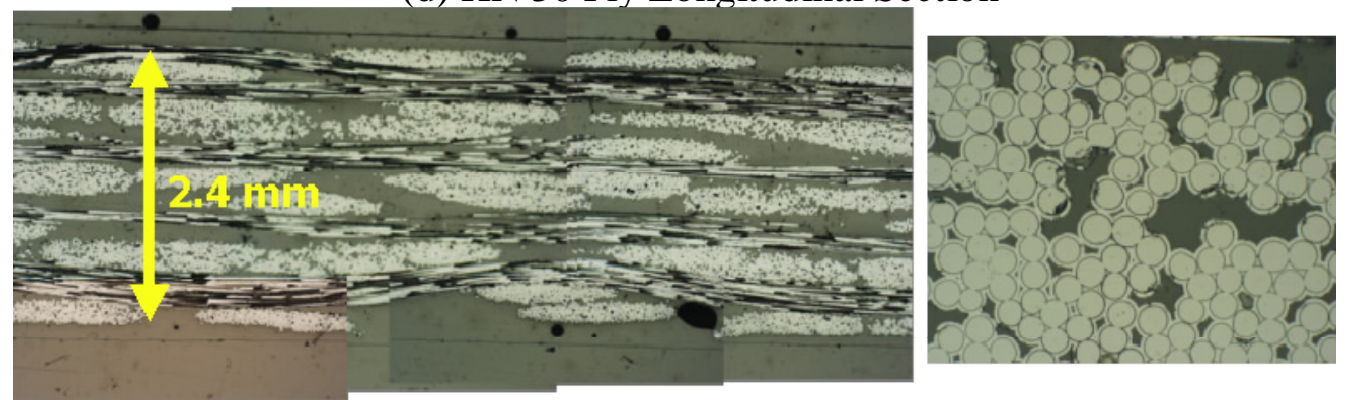

(e) HN E8Ply-8HS(BN) Longitudinal Section 


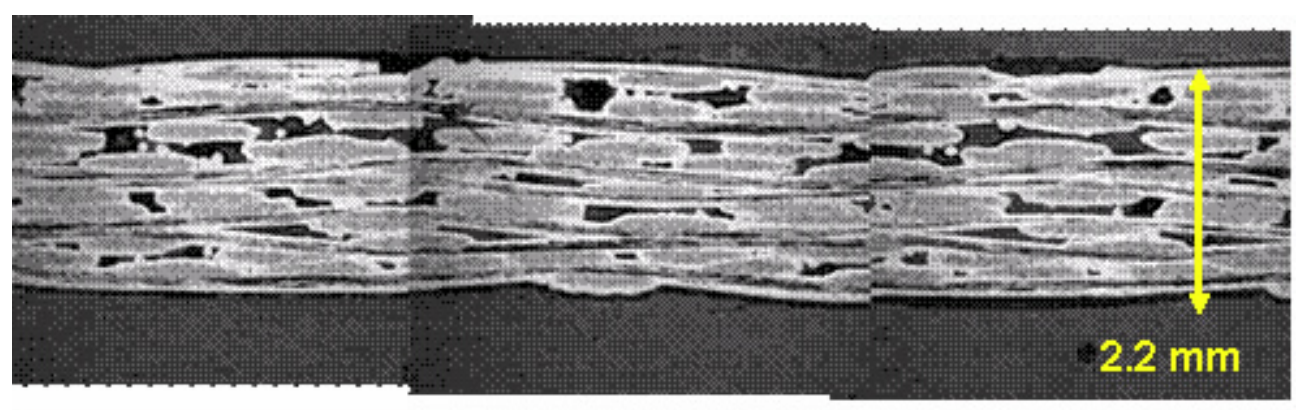

(f) Syl-iBN balanced 7.9 epcm

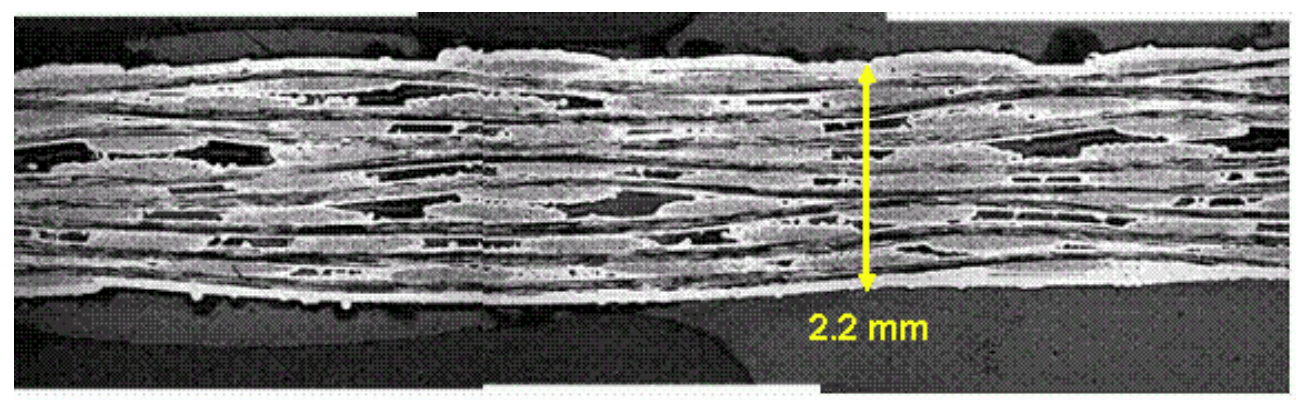

(g) Syl-iBN longitudinal (9.4 epcm) unbalanced

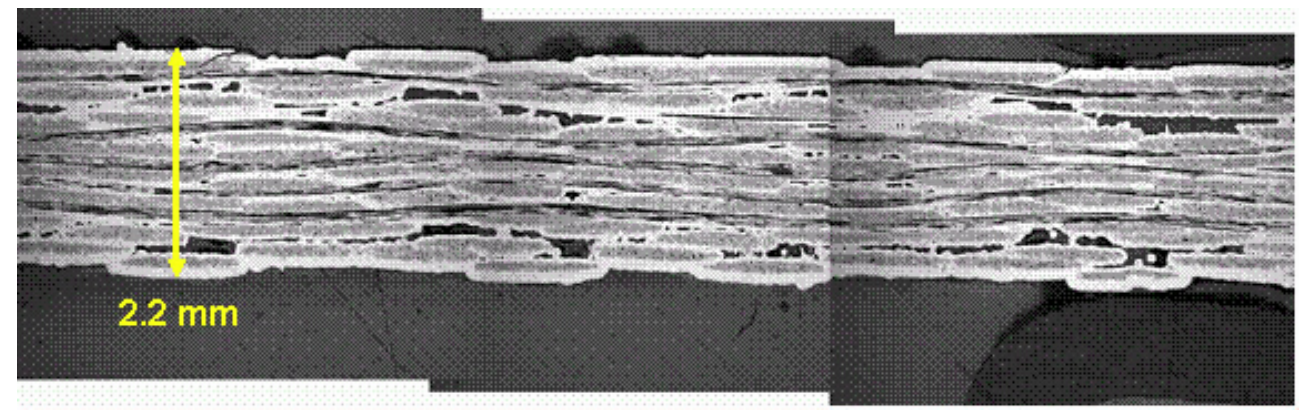

(h) Syl-iBN longitudinal (5.5 epcm) unbalanced

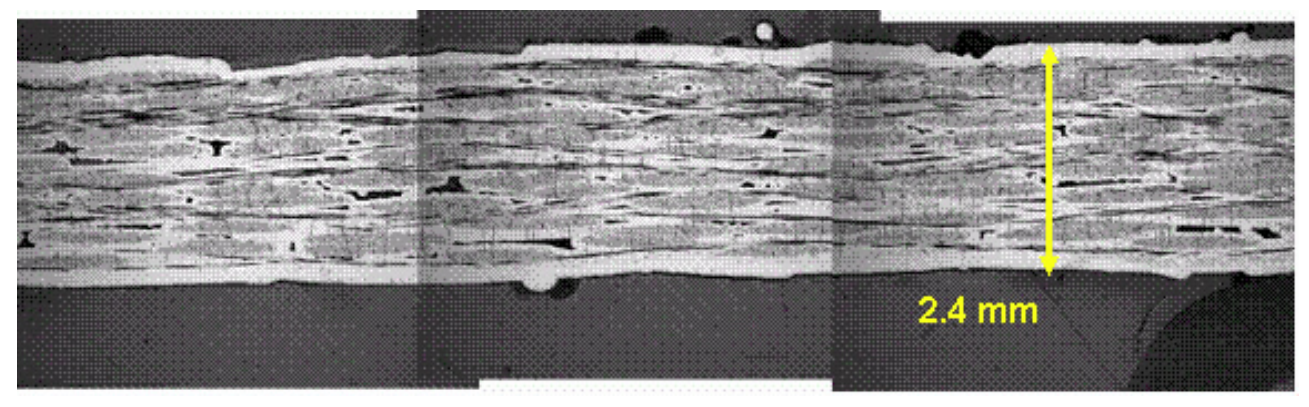

(i) Syl-iBN balanced $7.9 \mathrm{epcm}$ with carbon interphase

Figure 2: Microstructures of selected CVI SiC matrix composites. All of the specimens have a BN interphase except for (i). 


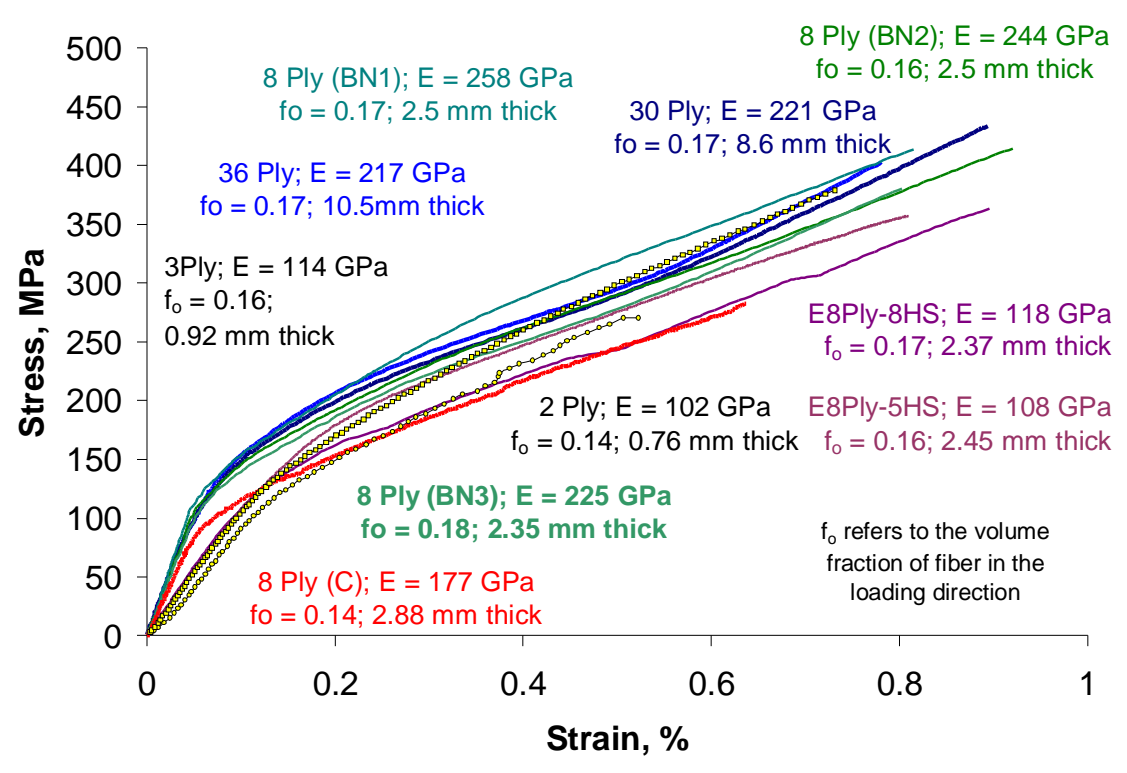

(a)

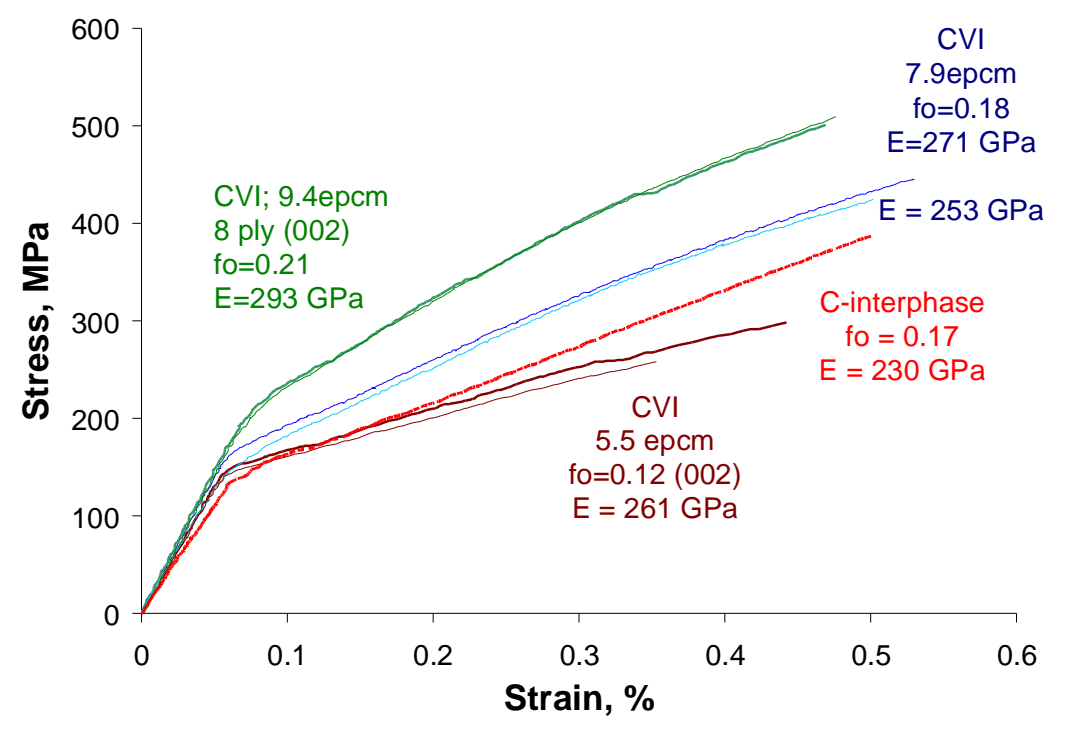

(b)

Figure 3: Tensile stress-strain behavior of (a) HN CVI SiC and (b) Syl-iBN CVI SiC composites. 


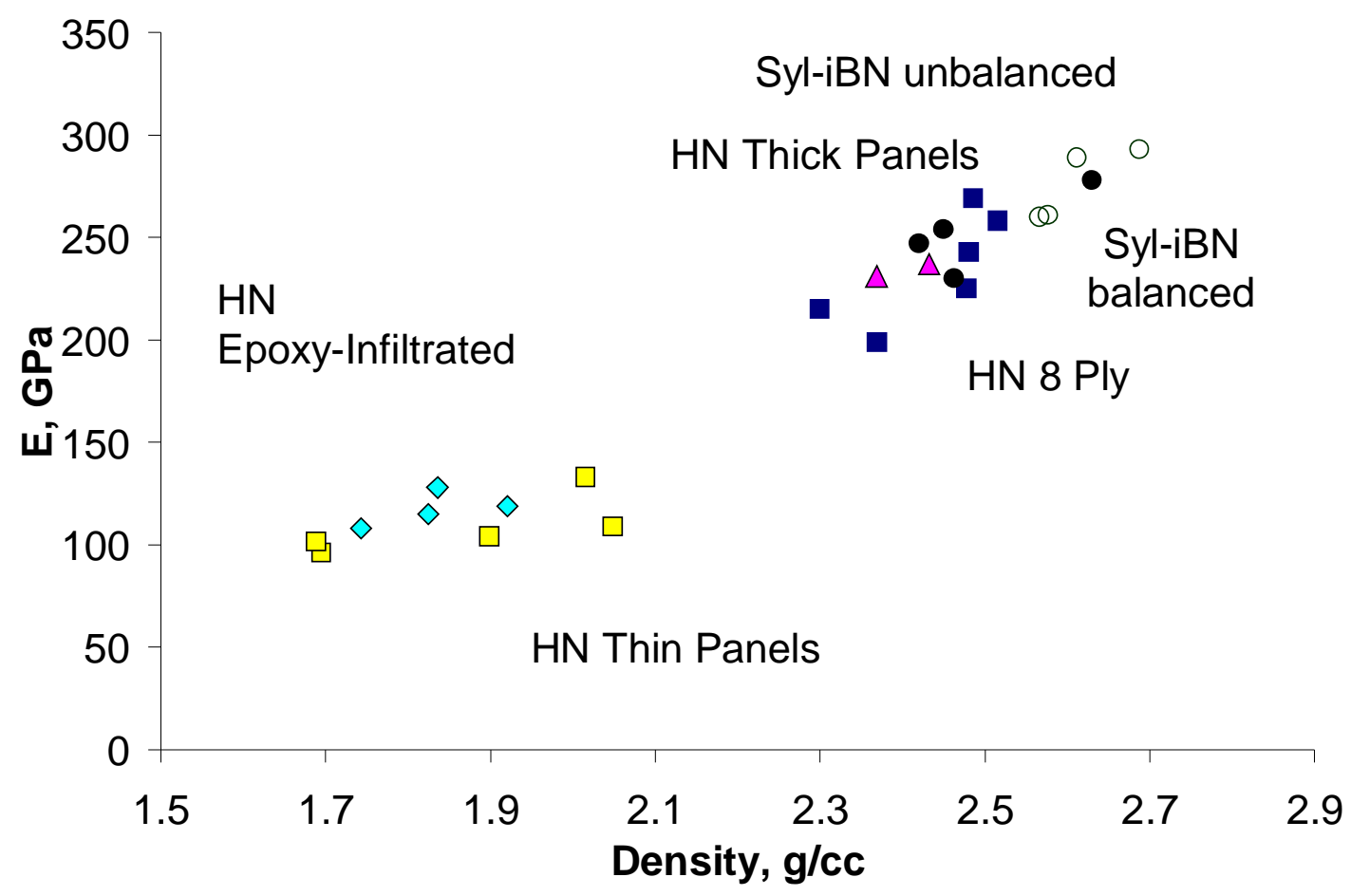

Figure 4: Effect of various physical properties on elastic modulus. 


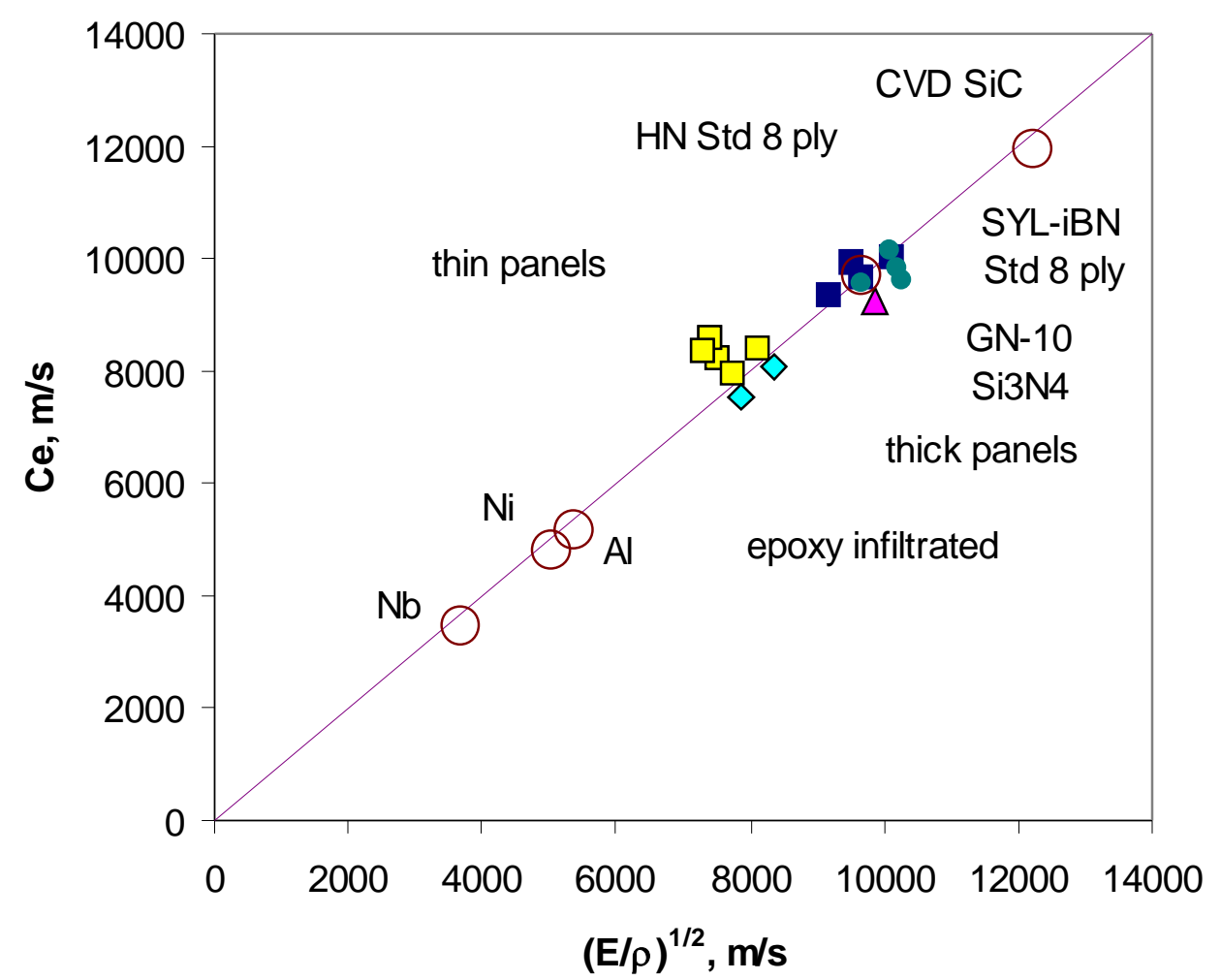

Figure 5: Measured speed of sound versus measured $(E / \rho)^{1 / 2}$. 


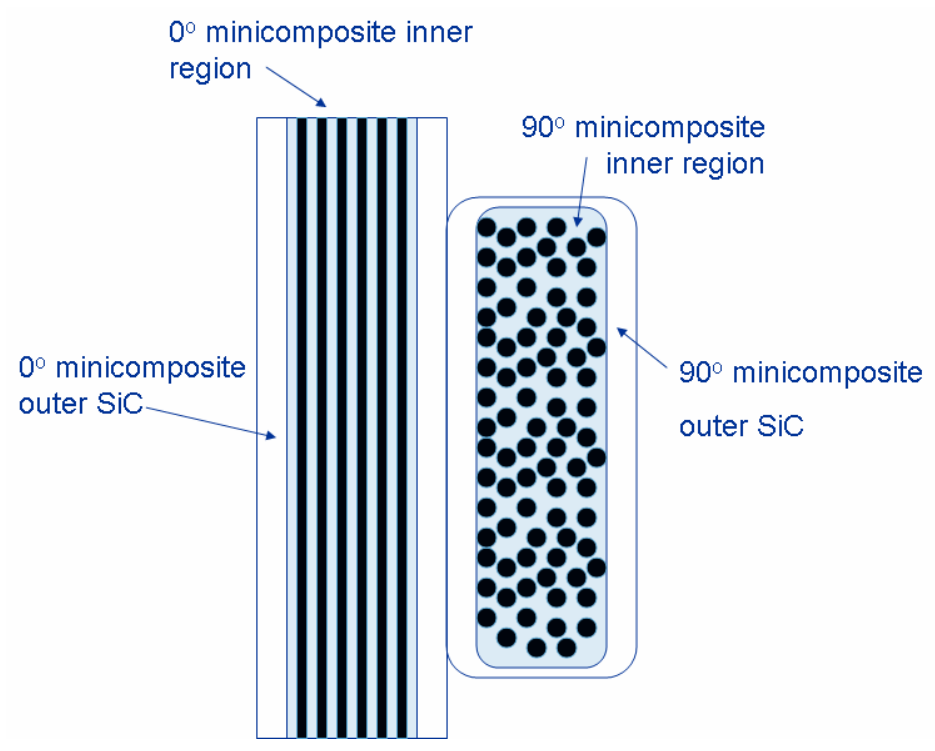

(a)

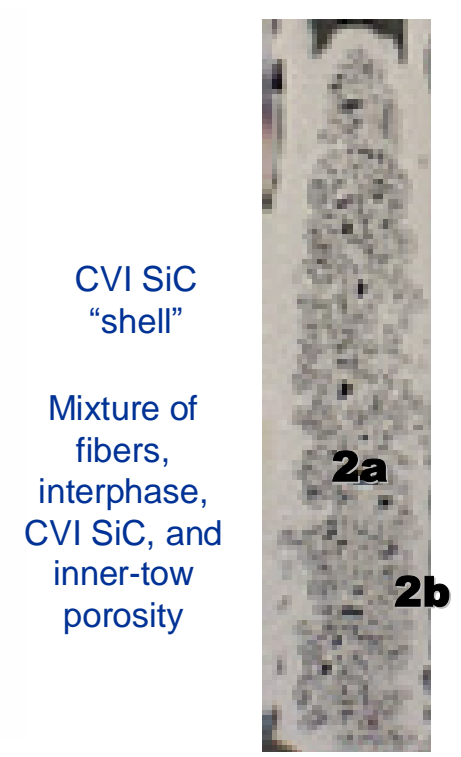

(b)

Figure 6: Schematic representation (a) of $0^{\circ}$ and $90^{\circ}$ minicomposite construction and (b) a typical $90^{\circ}$ minicomposite from HN 8PLY (BN3). 


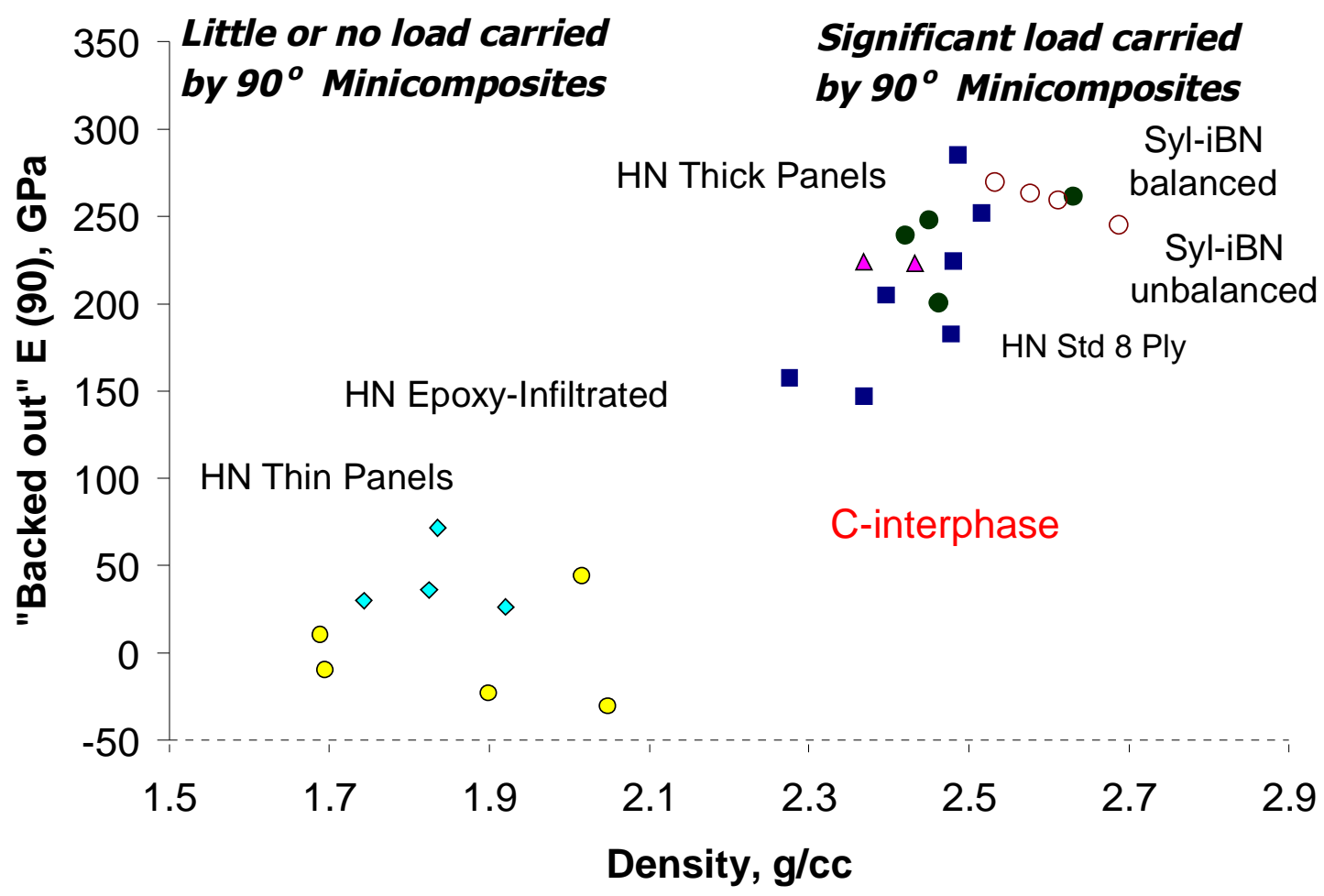

Figure 7: Effective elastic modulus of the $90^{\circ}$ minicomposites. 


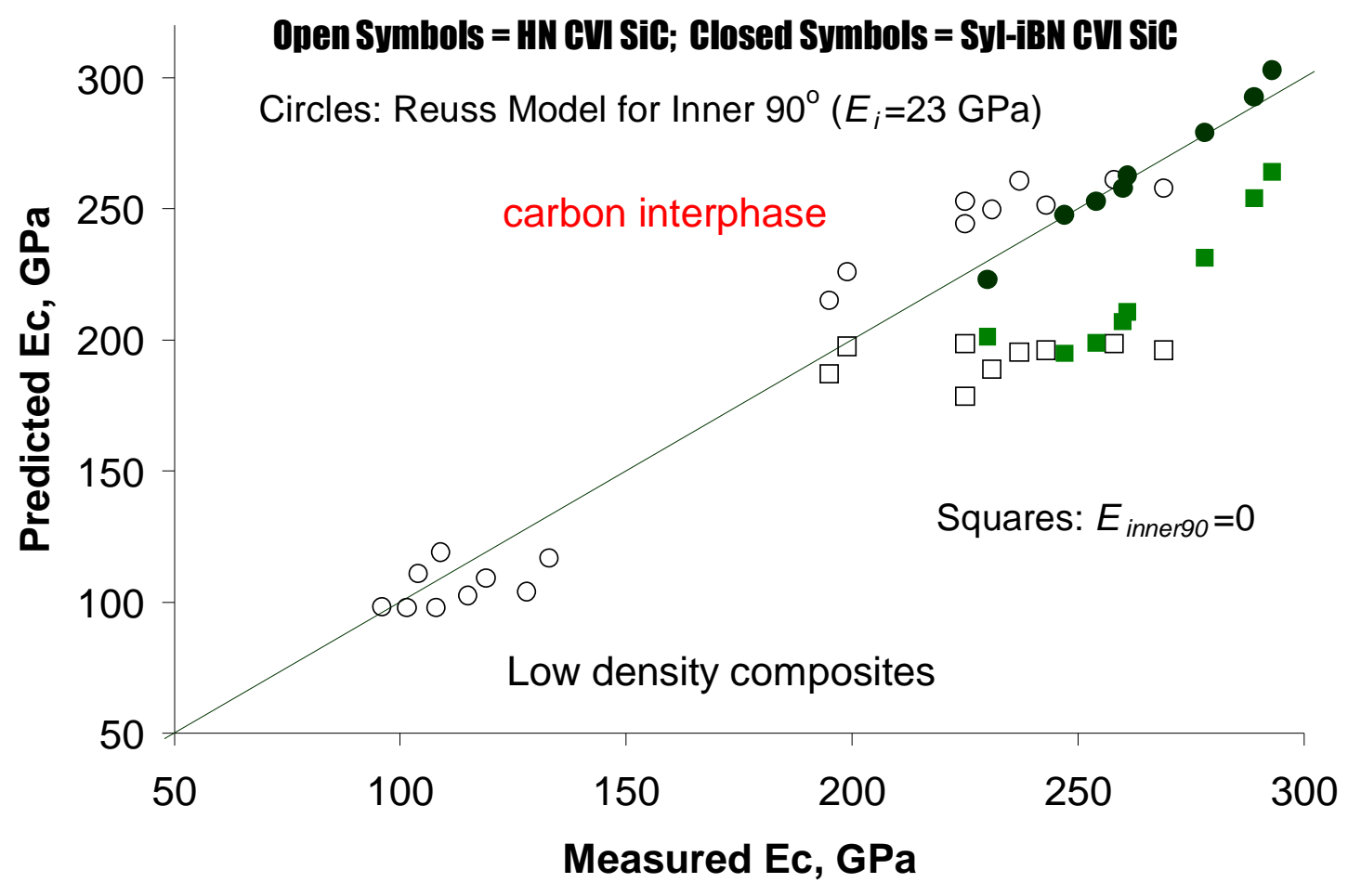

Figure 8: $\mathrm{E}_{\mathrm{c}}$ prediction. 